\title{
Evaluating Endotracheal Tube Depth in Infants Weighing Less Than 1 Kilogram
}

\author{
Renee M Bartle, Andrew G Miller, Anthony J Diez, P Brian Smith, Michael A Gentile, and \\ Mihai Puia-Dumitrescu
}

\begin{abstract}
BACKGROUND: Endotracheal tube (ETT) depth in premature infants is of critical importance because potentially life-threatening adverse events can occur if the tube is malpositioned. Analysis of current data indicates that the accuracy of current resuscitation guidelines for infants $<1 \mathrm{~kg}$ is poor. We hypothesized that a weight-based formula that is used clinically in our institution would accurately predict appropriate ETT placement in infants weighing $<1 \mathrm{~kg}$. METHODS: The medical records, from July 2013 to November 2016, of all infants $<1 \mathrm{~kg}$ who were intubated were retrospectively reviewed and included. The 2 formulas utilized were the Duke formulas $5.5 \mathrm{~cm}+1 \mathrm{~cm} / \mathrm{kg}$ for infants $500-999 \mathrm{~g}$ or $5.0+1 \mathrm{~cm} / \mathrm{kg}$ for infants $<500 \mathrm{~g}$. The appropriate ETT position was defined as the tip of the ETT below the thoracic inlet and above the carina, at approximately thoracic vertebrae 2 or 3 on an initial chest radiograph. The formula was defined as being accurate if the documented ETT depth was within $0.2 \mathrm{~cm}$ of the predicted depth. Post hoc analysis of current resuscitation guidelines $(6 \mathrm{~cm}$ plus the weight of the infant in $\mathrm{kg}$ ) was performed after the Duke formula performed worse than expected. RESULTS: A total of 131 subjects (mean \pm gestational age, $26 \pm 1.8 \mathrm{wk}$; mean \pm weight, $729 \pm 140 \mathrm{~g}$ ) were included. The documented depth was accurately predicted by the Duke formula for $47 \%$ of the subjects, with $69 \%$ of the ETTs appropriately positioned as seen on a chest radiograph. Sensitivity was $46.6 \%$, specificity was $\mathbf{5 3 . 6 \%}$, positive predictive value was $\mathbf{6 8 . 8 \%}$ and negative predictive value was $31.4 \%$ for the Duke formula. Post hoc analysis current resuscitation guidelines found that the documented depth was accurately predicted for $\mathbf{2 3 \%}$ infants, with $\mathbf{7 0 \%}$ of these appropriately positioned ETTs. CONCLUSIONS: Our weight-based, institutional formula had a low sensitivity for predicting proper ETT depth. Weight-based formulas may have clinical utility; however, analysis of current data did not support use in infants $<1 \mathrm{~kg}$. Rapid radiologic assessment of ETT placement is required for this patient population. Key words: endotracheal tube placement; neonates; premature neonates. [Respir Care 2019;64(3):243-247. (C) 2019 Daedalus Enterprises]
\end{abstract}

\section{Introduction}

Premature infants frequently require endotracheal intubation due to cardiopulmonary resuscitation, surfactant deficiency, poor respiratory effort, respiratory distress, or

\footnotetext{
Ms Bartle, Mr Miller, and Mr Diez are affiliated with Respiratory Care Services, Duke University Medical Center, Durham, North Carolina. Drs Smith and Puia-Dumitrescu are affiliated with the Division of Neonatology, Duke University Medical Center, Durham, North Carolina. Mr Gentile is affiliated with the Division of Pediatric Critical Care Medicine, Duke University Medical Center, Durham, North Carolina.
}

The authors have disclosed no conflicts of interest. apnea. Appropriate endotracheal tube (ETT) depth is critically important in premature neonates because ETT malpositioning can result in life-threatening adverse events, such as hypoxemia, pneumothorax, or inadvertent extubation. Overzealous manual ventilation at birth may also cause lung injury due to high tidal volumes and high ventilating pressures. Analysis of current data indicates that

\footnotetext{
Correspondence: Renee M Bartle RRT, Respiratory Care Services, Duke University Medical Center, 2301 Erwin Rd, Durham, NC 27710. E-mail: renee.bartle@duke.edu.
}

DOI: $10.4187 /$ respcare. 06202 
ETTs are malpositioned in as many as one third of infants ${ }^{1}$ and in $47 \%$ of infants $<1 \mathrm{~kg} .^{2}$

The immature lung is particularly vulnerable at birth due to surfactant deficiency and fluid-filled alveoli, which

See the Related Editorial on Page 350

carries an increased risk of pneumothorax due to low compliance. ${ }^{3}$ This risk is increased if the ETT is inadvertently inserted into a main bronchus. In addition, proper ETT positioning is critical for the delivery of endogenous surfactant therapy because endobronchial intubation will result in only a single lung receiving surfactant replacement. The Neonatal Resuscitation Program recommendations (American Academy of Pediatrics, Itasca, IL) for initial ETT depth have not been validated in infants $<1 \mathrm{~kg}$. Specifically, the Neonatal Resuscitation Program formula may result in an initial ETT depth that is too deep and may expose neonates to adverse events related to mainstem intubation. In clinical practice, our institution has used a weight-based formula for initial ETT depth for many years that differs from the Neonatal Resuscitation Program formula; however, this formula has not been validated. The purpose of this project was to evaluate the accuracy of this formula.

\section{Methods}

After institutional review board approval, we retrospectively identified, through electronic medical records, all infants weighing $<1 \mathrm{~kg}$ who required intubation between July 2013 and November 2016. Data were extracted on gestational age in weeks, birthweight, and ETT depth documented in the electronic medical record. Appropriate ETT position on chest radiograph (CXR) after initial intubation was defined as the tip of the ETT below the thoracic inlet and above the carina, at approximately thoracic vertebrae 2 or 3 . An ETT above the thoracic inlet was defined as high, and an ETT located below the carina was defined as low. The ETT position on CXR was determined independently by core respiratory therapist (RMB), and neonatology physician (MPD). It is our policy, in the intensive care nursery, to take CXRs with the head in a neutral position. Due to the retrospective nature of this study, we were unable to determine if there was any neck flexion. Unblinded clinicians (RMB, MPD) instead of blinded radiologists were used to reflect actual clinical practice because initial ETT positioning is based on assessment at the bedside in most instances.

In our facility, ETT depth is measured from the lip via direct visualization before ETT taping or via tape measure after the ETT is secured. We were unable to determine which method was used due to the retrospective nature of

\section{QUICK LOOK}

\section{Current knowledge}

Endotracheal tube (ETT) depth in premature infants is of critical importance as potentially life-threatening adverse events can occur if the tube is malpositioned. Analysis of current data indicated that the accuracy of the Neonatal Resuscitation Program formula for infants $<1 \mathrm{~kg}$ was poor. There is a need for improved formulas for this patient population.

\section{What this paper contributes to our knowledge}

A weight-based, institutional formula used clinically had a low sensitivity for predicting proper ETT depth. Weight-based formulas may have clinical utility; however, analysis of current data indicated that their accuracy was poor in infants $<1 \mathrm{~kg}$. Rapid radiologic assessment of ETT placement is necessary.

this study. After determining the documented initial ETT depth, we calculated the predicted ETT depth by using the subject's birthweight and the Duke formula.

\section{Duke Formula}

- Infants between 500 and $999 \mathrm{~g}: 5.5 \mathrm{~cm}+1 \mathrm{~cm} / \mathrm{kg}$ Duke formulas by using patient's current weight.

- Infants $<500 \mathrm{~g}: 5.0 \mathrm{~cm}+1 \mathrm{~cm} / \mathrm{kg}$ Duke formulas by using patient's current weight.

The primary outcome for each version of the formula was the proportion of ETTs appropriately positioned on a CXR. We determined that the Duke formula was met if the predicted ETT depth was within $2 \mathrm{~mm}$ of the documented depth. The position on a CXR was classified as good, high, or low. Results for weight, gestational age, and position on a CXR were subsequently compared for the subjects in whom the predicted rule was or was not met. When our rule failed to perform as well as expected, a post hoc analysis of the Neonatal Resuscitation Program formula $(6 \mathrm{~cm}+1 \mathrm{~cm} / \mathrm{kg})$ was performed by using the same methodology as mentioned above.

Data were analyzed by using SPSS software v24 (SPSS, Chicago, Illinois). Chi-square and the unpaired $t$ test were performed for categorical and continuous data, as appropriate. Specificity, sensitivity, and positive and negative predictive values were also calculated. By using only ETTs in the appropriate position on a CXR, we compared the actual mean initial ETT depth with the depth predicted by each formula. Statistical significance was defined as $\alpha<0.05$. 
Table 1. Demographics

\begin{tabular}{lcc}
\hline \hline \multicolumn{1}{c}{ Variable } & $\begin{array}{c}\text { All } \\
\text { Infants }\end{array}$ & $\begin{array}{c}\text { Correctly } \\
\text { Positioned ETT }\end{array}$ \\
\hline Infants, $n$ & 131 & 90 \\
Gestational age, mean \pm SD, wk & $26 \pm 1.8$ & $26 \pm 1.8$ \\
Weight, mean \pm SD, g & $729 \pm 140$ & $732 \pm 139$ \\
ETT $=$ endotracheal tube & & \\
\hline
\end{tabular}

Table 2. Results for the Duke Formula

\begin{tabular}{|c|c|c|c|}
\hline \multirow{2}{*}{$\frac{\text { Variable }}{\text { Formula Prediction Met }}$} & \multicolumn{2}{|c|}{ Duke Formula } & \\
\hline & Yes & No & \\
\hline Infants, $n / N(\%)$ & $61 / 131(47)$ & $70 / 131(53)$ & NA \\
\hline Gestational age, mean $\pm \mathrm{SD}$, wk & $25 \pm 1.8$ & $26 \pm 1.7$ & .34 \\
\hline Weight, mean $\pm \mathrm{SD}, \mathrm{g}$ & $725 \pm 130$ & $731 \pm 147$ & .79 \\
\hline ETT depth, mean $\pm \mathrm{SD}, \mathrm{cm}$ & $6.2 \pm 0.3$ & $6.4 \pm 0.5^{*}$ & .02 \\
\hline \multicolumn{4}{|l|}{ Radiographic positioning, $n(\%)$} \\
\hline Good & $42(69)$ & $48(69)$ & .86 \\
\hline High & $12(20)$ & $12(17)$ & \\
\hline Low & $7(12)$ & $10(14)$ & \\
\hline \multicolumn{4}{|c|}{$\begin{array}{l}\text { * Defined as tip of the ETT positioned between the thoracic inlet and above the carina, at } \\
\text { approximately thoracic vertebrae } 2 \text { or } 3 . \\
\text { ETT = endotracheal tube } \\
\text { NA = not applicable }\end{array}$} \\
\hline
\end{tabular}

\section{Results}

A total of 131 subjects met our inclusion criteria. The mean \pm SD gestational age was $26 \pm 1.8$ weeks with a birthweight of $729 \pm 140 \mathrm{~g}$. Demographic data are summarized in Table 1. The Duke formula was met for $47 \%$ of the infants (61/131). There was no statistical significant difference between the proportion of ETTs appropriately positioned, whether or not the Duke formula was met (69\% vs $69 \%, P=.86$ ). Sensitivity was $46.6 \%$, specificity was $53.6 \%$, the positive predictive value was $68.8 \%$, and the negative predictive value was $31.4 \%$ for the Duke formula. Results are summarized in Table 2. In the post hoc analysis of the Neonatal Resuscitation Program formula, the predicted depth formula prediction was met for $23 \%$ of the infants (30/131). The results are summarized in Table 3.

ETTs were positioned appropriately in 90 infants. When analyzing only those ETTs that were appropriately positioned on the initial CXR, the mean \pm SD documented depth was $6.3 \pm 0.4 \mathrm{~cm}$ (the Duke formula predicted mean $\pm \mathrm{SD} 6.2 \pm 0.2 \mathrm{~cm}$ vs $6.7 \pm 0.1 \mathrm{~cm}$ for Neonatal Resuscitation Program formula). The Duke formula prediction provided a closer approximation of the actual ETT depth (47\% [42/90]) than the Neona-
Table 3. Results for the Neonatal Resuscitation Program Formula

\begin{tabular}{|c|c|c|c|}
\hline \multirow{2}{*}{$\begin{array}{l}\text { Variable } \\
\text { Formula Prediction Met }\end{array}$} & \multicolumn{2}{|c|}{$\begin{array}{l}\text { Neonatal } \\
\text { Resuscitation Program }\end{array}$} & \multirow{2}{*}{$P$} \\
\hline & Yes & No & \\
\hline Infants, $n / N(\%)$ & $30 / 131(23)$ & 101/131 (77) & NA \\
\hline $\begin{array}{l}\text { Gestational age, } \\
\text { mean } \pm \mathrm{SD}, \mathrm{wk}\end{array}$ & $26 \pm 1.7$ & $25 \pm 1.7$ & .63 \\
\hline Weight, mean $\pm \mathrm{SD}, \mathrm{g}$ & $725 \pm 161$ & $730 \pm 133$ & .88 \\
\hline $\begin{array}{l}\text { Documented ETT depth, } \\
\text { mean } \pm \mathrm{SD}, \mathrm{cm}\end{array}$ & $6.7 \pm 0.2$ & $6.2 \pm 0.4^{*}$ & $<.001$ \\
\hline \multicolumn{4}{|l|}{ Radiographic positioning, $n(\%)$} \\
\hline Good & $21(70)$ & $69(68)$ & .85 \\
\hline High & $6(20)$ & $18(18)$ & \\
\hline Low & $3(10)$ & $14(14)$ & \\
\hline \multicolumn{4}{|c|}{$\begin{array}{l}\text { * Defined as tip of the ETT positioned between the thoracic inlet and above the carina, at } \\
\text { approximately thoracic vertebrae } 2 \text { or } 3 . \\
\text { NA }=\text { not applicable } \\
\text { ETT = endotracheal tube }\end{array}$} \\
\hline
\end{tabular}

tal Resuscitation Program formula prediction $(23 \%$ [21/90]). In particular, the Neonatal Resuscitation Program formula would have resulted in the average ETT being placed $0.4 \pm 0.1 \mathrm{~cm}$ deeper than the actual documented depth.

\section{Discussion}

Our study evaluated the ETT depth in 131 premature infants weighing $<1 \mathrm{~kg}$. The Duke formula provided a closer estimate when compared with the Neonatal Resuscitation Program formula rule when only appropriately positioned ETTs were considered; however, overall, neither formula performed well enough to be considered a reliable indicator of ETT depth in infants $<1 \mathrm{~kg}$. We found that the Duke formula prediction was met for $46 \%$ of our subjects with no difference in appropriately placed ETTs when the Duke prediction formula was not met. Our results found that the formula was followed in fewer than half of subjects, which indicated that either the formula was not being closely followed in the delivery room or that the ETT depth was being adjusted clinically before the initial CXR. This indicated that our formula was not as closely followed in clinical practice as we believed. Importantly, the Neonatal Resuscitation Program formula prediction seemed to significantly overestimate ETT depth in infants $<1 \mathrm{~kg}$.

Confirmation of proper ETT placement should be completed in all patients at the time of initial intubation. A combination of physical examination methods, fogging in the tube, pulse oximetry, end-tidal carbon dioxide detector, and CXR should be used. These methods only confirm placement in the trachea; currently, radiographic confir- 
mation is needed to evaluate ETT depth. Newer devices are in development to evaluate ETT depth by using acoustic reflectometry but have not, to our knowledge, been used to evaluate neonates. ${ }^{4}$ Ultrasound imaging may be used to reliably confirm ETT placement but requires specialized equipment, training, and experience in this technique. ${ }^{5}$ Ultrasound was not in use at our institution during this study. Ideally, a simple formula to determine ETT depth in premature infants would be used; however, there is no formula currently available. Endobronchial intubation and subsequent unilateral surfactant delivery increases infant morbidity and mortality. Pulmonary interstitial emphysema, pneumothorax, and atelectasis can also result from inappropriately placed ETT. 3,6,7

The original formula described by Tochen ${ }^{8}$ is widely known as the 7-8-9 rule for infants 1,2 , and $3 \mathrm{~kg}$, respectively as weight increases, so does the depth of the ETT. This rule is widely used and is included in the Neonatal Resuscitation Program formula guidelines for ETT depth. ${ }^{9}$ Peterson et $\mathrm{al}^{10}$ found that this rule performed well for infants $>750 \mathrm{~g}$ but poorly for those $<750 \mathrm{~g}$. We found that neither the Duke nor Neonatal Resuscitation Program formulas for initial placement performed well for infants $<1 \mathrm{~kg}$, although the Duke formula provided a closer depth when only appropriately placed ETTs were included. There was no significant correlation between subject weight and ETT depth for appropriately placed ETTs, consistent with the results of Kembley et al, ${ }^{11}$ who found that the appropriate ETT depth was linear with gestational age but logarithmic with weight. Because a 24 -wk premature infant has an approximated tracheal length of $26.87 \mathrm{~mm}$ (pre-bifurcation and bifurcation length together), the $0.4 \mathrm{~cm}$ difference in ETT depth between the Duke formula and the Neonatal Resuscitation Program formula can have deleterious effects. ${ }^{12}$

Flinn et $\mathrm{al}^{13}$ examined this question in a randomized trial by using either gestational age or birthweight and found no differences in correctly positioned ETTs between the groups. Importantly, this trial found that $51 \%$ of ETTs were malpositioned when depth was determined by weight (by using the Neonatal Resuscitation Program formula rule) compared with $39 \%$ when gestational age was used..$^{13}$ Amarilyo et $\mathrm{al}^{2}$ found similar results in 31 infants $<1 \mathrm{~kg}$; however, they adjusted the ETT depth based on auscultation and found, on CXR, that $74 \%$ of ETTs were well positioned. ETT placement was significantly deeper in subjects for whom the Duke formula prediction was not met, which indicated that either the rule was not being followed closely in the stressful environment of the delivery room or the ETT was repositioned based on clinical assessment. Peterson et $\mathrm{al}^{10}$ validated the 7-8-9 rule in a cohort of 75 infants and found that this rule performed well for infants $>750 \mathrm{~g}$. For 17 infants $<750 \mathrm{~g}$, the formula was found to be significantly inaccurate, with the ETT positioned between 0.3 and $0.9 \mathrm{~cm}$ too deep. ${ }^{10}$

Sakhuja et al ${ }^{14}$ performed a survey of clinical practice that revealed that the majority of respondents (87\%) used the Neonatal Resuscitation Program formula or inserted the ETT past the black vocal cord marking to estimate ETT depth. Although the results of the study by Kempley et al, ${ }^{11}$ and supported by our results, indicate that weight-based formulas are inadequate for infants $<1 \mathrm{~kg}$, these studies were relatively small, single-center studies. ${ }^{11}$ Flinn et al ${ }^{13}$ directly compared the 2 methods and found neither to be superior; however, this study was underpowered to detect differences in the ETT position because they only enrolled 90 infants in total. A large, multi-center trial is clearly needed to better evaluate which method (weightbased formula or gestational age) is superior.

Leung ${ }^{15}$ recently investigated ETT depth in infants $<1 \mathrm{~kg}$ and found that birthweight, gestational age, and body length were all linearly correlated with the ETT depth. The strongest correlation was with birthweight; however, the $\mathrm{R}^{2}$ value was only $0.497, R^{2}$ was 0.458 for body length and $\mathrm{R}^{2}$ gestational age was 0.338 . It was found that body weight was a reasonable starting point, body length could be used as an alternative but the most appropriate method to confirm ETT position was with rapid radiographic confirmation. ${ }^{15}$ Our results confirmed that ETT depth was poorly correlated with birthweight; thus analysis of current data indicated that weight-based formulas were inadequate to evaluate ETT depth in infants $<1 \mathrm{~kg}$.

Our study had several limitations. As a retrospective review, data were limited to data available in the medical record. Measurement of ETT depth at the lip may have varied among respiratory therapists. Use of the formula and the proper head positioning during CXR were unable to be controlled by study personnel. ETT depth may have been adjusted based on clinical grounds before the initial CXR; however, these data were unavailable in our medical record. Prompt radiologic confirmation continues to be viewed as most appropriate in determining ETT placement. A prospective study is needed to confirm and better control for these issues.

\section{Conclusions}

A weight-based institutional formula used clinically had a low sensitivity for predicting proper ETT depth. Weightbased formulas may have clinical utility; however, analysis of current data indicated that the accuracy of these formulas was poor in infants $<1 \mathrm{~kg}$. Rapid radiologic assessment of ETT placement is necessary.

\section{REFERENCES}

1. Saboo AR, Dutta S, Sodhi KS. Digital palpation of endotracheal tube tip as a method of confirming endotracheal tube position in neonates: 
an open-label, three-armed randomized controlled trial. Paediatr Anaesth 2013;23(10):934-939.

2. Amarilyo G, Mimouni FB, Oren A, Tsyrkin S, Mandel D. Orotracheal tube insertion in extremely low birth weight infants. J Pediatr 2009;154(5):764-765.

3. Niwas R, Nadroo AM, Sutija VG, Gudavalli M, Narula P. Malposition of endotracheal tube: association with pneumothorax in ventilated neonates. Arch Dis Child Fetal Neonatal Ed 2007;92(3):F233-F234.

4. Nacheli GC, Sharma M, Wang X, Gupta A, Guzman JA, Tonelli AR. Novel device (AirWave) to assess endotracheal tube migration: a pilot study. J Crit Care 2013;28(4):535.e1-e8.

5. Sharma D, Tabatabaii SA, Farahbakhsh N. Role of ultrasound in confirmation of endotracheal tube in neonates: a review. J Matern Fetal Neonatal Med 2017;1-9.

6. Pinheiro JM, Munshi UK. Factors contributing to endobronchial intubation in neonates. Pediatr Crit Care Med 2015;16(1):54-58.

7. Thayyil S, Nagakumar P, Gowers H, Sinha A. Optimal endotracheal tube tip position in extremely premature infants. Am J Perinatol 2008;25(1):13-16.

8. Tochen ML. Orotracheal intubation in the newborn infant: a method for determining depth of tube insertion. J Pediatr 1979;95(6):1050-1051.

9. Kattwinkel J, Perlman JM, Aziz K, Colby C, Fairchild K, Gallagher J, et al.; American Heart Association. Neonatal resuscitation: 2010
American Heart Association Guidelines for Cardiopulmonary Resuscitation and Emergency Cardiovascular Care. Pediatrics 2010; 126(5):e1400-e1413.

10. Peterson J, Johnson N, Deakins K, Wilson-Costello D, Jelovsek JE, Chatburn R. Accuracy of the 7-8-9 Rule for endotracheal tube placement in the neonate. J Perinatol 2006;26(6):333-336.

11. Kempley ST, Moreiras JW, Petrone FL. Endotracheal tube length for neonatal intubation. Resuscitation 2008;77(3):369-373.

12. Szpinda M, Daroszewski M, Woźniak A, Szpinda A, Mila-Kierzenkowska C. Tracheal dimensions in human fetuses: an anatomical, digital and statistical study. Surg Radiol Anat 2012;34(4): 317-323.

13. Flinn AM, Travers CP, Laffan EE, O'Donnell CP. Estimating the endotracheal tube insertion depth in newborns using weight or gestation: a randomised trial. Neonatology 2015;107(3):167-172.

14. Sakhuja P, Finelli M, Hawes J, Whyte H. Is It Time to Review Guidelines for ETT Positioning in the NICU? SCEPTIC-Survey of Challenges Encountered in Placement of Endotracheal Tubes in Canadian NICUs. Int J Pediatr 2016;2016:1-8.

15. Leung C. Optimal insertion depth for endotracheal tubes in extremely low-birth-weight infants. Pediatr Crit Care Med 2018;19(4):328-331.

This article is approved for Continuing Respiratory Care Education credit. For information and to obtain your CRCE

(free to AARC members) visit

www.rcjournal.com 